\title{
THE PROTECTIVE EFFECTS OF ECHINOPS HETEROPHYLLUS EXTRACT AGAINST METHOTREXATE-INDUCED HEPATOTOXICITY IN RABBITS
}

\author{
HEBA ABDULMOHSIN ${ }^{1 *}$, AHMED ABU RAGHIF ${ }^{1}$, MOHAMMED JABBAR MANNA ${ }^{2}$ \\ ${ }^{1}$ Department of Pharmacology, College of Medicine, Al-Nahrain University, Baghdad, Iraq. ${ }^{2}$ Department of Pharmacology, College of \\ Dentistry, Al-Mustansiriya University, Baghdad, Iraq. Email: heba.abd.ph@gmil.com
}

Received: 10 October 2018, Revised and Accepted: 26 November 2018

\section{ABSTRACT}

Objective: The aim of this study was to investigate antioxidant and hepatoprotective properties of Iraqi Echinops heterophyllus aqueous crude extract and its flavonoid fraction against methotrexate (MTX)-induced hepatotoxicity in rabbits.

Methods: MTX-induced hepatotoxicity by administration of $20 \mathrm{mg} / \mathrm{kg}$ MTX intraperitoneally for 3 successive days was used as animal model, and animals were arrayed in four groups with eight animals in each group: Group 1 was the healthy control, Group 2 - the negative control receiving MTX only, Group 3 received MTX+crude extract of E. heterophyllus, and Group 4 administered MTX+flavonoid fraction of E. heterophyllus. The study duration was 10 days; at day 11, animals were sacrificed, and the blood samples were obtained for the measurement of serum aspartate aminotransferase, alanine aminotransferase, alkaline phosphatase, total bilirubin, total protein, and albumin as well as ELISA assay of the oxidative stress markers such as glutathione (GSH) and malondialdehyde (MDA). The liver was dissected and processed for histopathological investigation and scoring. Statistical analysis was performed to investigate the significance of each result.

Results: The study results revealed severe liver damage due to MTX administration in the negative control (induced-non treated) group in comparison with healthy group, also there was significant hepatoprotective effect after administration of the crude extract of E. heterophyllus, and flavonoids fraction from Echinops heterophyllus as shown after measuring the biochemical liver function tests, as well as anti-oxidant properties demonstrated by the measurement of oxidative stress markers MDA and GSH in serum. The crude extract of E. heterophyllus shown superior hepatoprotective and antioxidant effect. Histopathological scoring showed a remarkable decrease in the scores of the treatment groups in comparison with the high score in the MTX only treated group.

Conclusions: MTX administered in a dose of $20 \mathrm{mg} / \mathrm{kg}$ for 3 successive days causes marked liver injury, while treatment with the crude extract and flavonoid fraction of E. heterophyllus significantly ameliorates MTX-induced liver damage, although the crude extract of E. heterophyllus seems to have the most hepatoprotective properties.

Keywords: Echinops heterophyllus, Flavonoids, Methotrexate, Hepatotoxicity, Antioxidant, Hepatoprotective.

(C) 2019 The Authors. Published by Innovare Academic Sciences Pvt Ltd. This is an open access article under the CC BY license (http://creativecommons. org/licenses/by/4. 0/) DOI: http://dx.doi.org/10.22159/ajpcr.2019.v12i1.30213

\section{INTRODUCTION}

Methotrexate (MTX), a folate pathway antagonist, is used in the treatment of a diversity of neoplasms, including leukemias as well as solid tumors [1]. It can cause diverse toxic effects on many body organs such as bone marrow, skin, mucosal membranes, and gastrointestinal tract [2], but its most disabling toxic effect is hepatotoxicity, represented as increased transaminases, hepatitis, fibrosis, and cirrhosis. Despite some vagueness regarding the mechanism of MTX-induced liver injury, it is believed that the oxidative stress and resultant inflammatory response are the main causes [3].

Echinops heterophyllus from Family Compositae/Asteraceae (Botanical Name: E. heterophyllus P.H.Davis), its English name is Globe thistle and Arabic name: Teskra, chouk el hmir, chouk el djamal, and sorr, is a plant native in Iraq, In Hanara village and surrounding area in Wadi Bastora and Shaklawa in Erbil Governorate, the plant is called (Shakroka). The term Shakroka comes from the circle-like part of the plant, which has sweet taste. It is a perennial, 40-100 cm high (Fig. 1) [4]

Phytochemical investigation of wild Iraqi E. heterophyllus shown the presence of alkaloids, flavonoids, terpenoids, and steroids in the different plant parts, and in different percentages, aerial parts contain the maximum quantity of flavonoids, while seeds contain the peak amount of alkaloids. A study established the helpful effect of E. heterophyllus on the wound healing and proposed its potential as an antimicrobial and anti-scar agent [4]. The presence of sitosterol in
E. heterophyllus and investigating its antimicrobial activity in vitro were reported for the first time in a study which explored the antibacterial action and the ability of purified and isolated sitosterols from this plant, compared it with $\mathrm{MEBO}^{\circledR}$ and gentamicin, and found it to have MEBOß’s same active ingredient phytosterols "chiefly sitosterol" [5].

The main objective of this study was to investigate the antioxidant and hepatoprotective properties of E. heterophyllus extract against MTXinduced hepatotoxicity.

\section{METHODS}

\section{Chemicals}

The vials of MTX were commercially acquired from the pharmacy. All the chemicals and reagents used for conducting the experiments were analytically graded.

\section{Animals}

The study was conducted from March 2018 to May 2018 at the Department of Pharmacology, College of Medicine, AL Nahrain University. The experiments were approved by the Institutional Review Board at the College of Medicine, AL Nahrain University. Domestic rabbits aged 4-6 months and weighing 1-1.5 kg of both sexes were used in this study. They were housed in the animal house in cages, which was provided with a wire mesh floor. Before starting the study, the animals were left for $72 \mathrm{~h}$ to acclimatize to the animal room conditions with a $12 \mathrm{~h}$ light/dark cycle. All rabbits had free access to food and tap water. 


\section{E. heterophyllus extraction}

Aerial parts of the plant were purchased from Duhok in the North of Iraq and identified by the National Iraqi Institute for Herbs. The extraction was done in the College of Pharmacy, Baghdad University.

1. Shade-dried coarsely powdered aerial parts of plant (130 g) were extracted with $300 \mathrm{ml}$ of $90 \%$ ethanol in reflex apparatus until complete exhaustion.

2. The alcoholic extract was evaporated under reduced pressure at a temperature below $40^{\circ} \mathrm{C}$ to give a dark greenish-yellow residue designated as a crude fraction 1 (F1).

3. Part of the crude fraction was acidified with hydrochloric acid (5\%) to $\mathrm{pH} 2$ and partitioned (3 times) with an equal volume of ethyl acetate.

4. The ethyl acetate layer was evaporated to dryness under reduced pressure and basified with $300 \mathrm{ml}$ of sodium hydroxide $5 \%$ to $\mathrm{pH} 10$ and extracted with chloroform.

5. The aqueous basic layer was separated, evaporated to dryness, acidified with $5 \%$ hydrochloric acid to $\mathrm{pH} 2$, and then extracted with ethyl acetate to get fraction designated as fraction 2 (F2) which contains the flavonoids [4].

Qualitative estimation of flavonoid compounds of E. heterophyllus using high-performance liquid chromatography (HPLC)

The flavonoid compound of $E$. heterophyllus was determined by a Waters 2695 HPLC system (Meadows Instrumentation, Illinois) and 2487 ultraviolet detector with ODS column $(250 \mathrm{~mm} \times 4.6 \mathrm{~mm}, 5 \mu \mathrm{m}) .1 \mathrm{mg}$ of flavonoid fraction was dissolved in $5 \mathrm{ml} \mathrm{70 \%} \mathrm{methanol} \mathrm{and} \mathrm{detected}$ at $320 \mathrm{~nm}$ at a flow rate of $1 \mathrm{ml} / \mathrm{min}$. The data were analyzed with the previously mentioned standards prepared as a solution mixture containing $0.5 \mathrm{mg} / 1 \mathrm{ml}$ of standards in methanol and performed as a single run in HPLC.

\section{Experimental design}

Animals were allocated randomly into four groups (eight animals in each group). MTX toxicity was induced in each group of animals (except healthy control group) by injection of MTX $20 \mathrm{mg} / \mathrm{kg}$ intraperitoneally i.p. [6] for 3 successive days. The total time span for the study was 10 days.

The study groups included:

- Group I: The animals were given distilled water (D.W) orally for 10 days, sacrificed on day 11, and served as healthy controls.

- Group II: The animals were given D.W orally for 10 days. MTX $(20 \mathrm{mg} / \mathrm{kg})$ i.p was injected on $3^{\text {rd }}, 4^{\text {th }}$, and $5^{\text {th }}$ days, and the animals were sacrificed on day 11 and served as negative controls.

- Group III: The animals were given Echinops crude extract (F1) orally $250 \mathrm{mg} / \mathrm{kg}$ once daily for 10 days. On $3^{\text {rd }}$ day hepatotoxicity induced as in Group II, the animals were sacrificed on day 11.

- Group IV: The animals were given Echinops flavonoid extract (F2) orally $250 \mathrm{mg} / \mathrm{kg}$ [7] once daily for 10 days. On $3^{\text {rd }}$ day hepatotoxicity induced as in Group II, the animals were sacrificed on day 11.

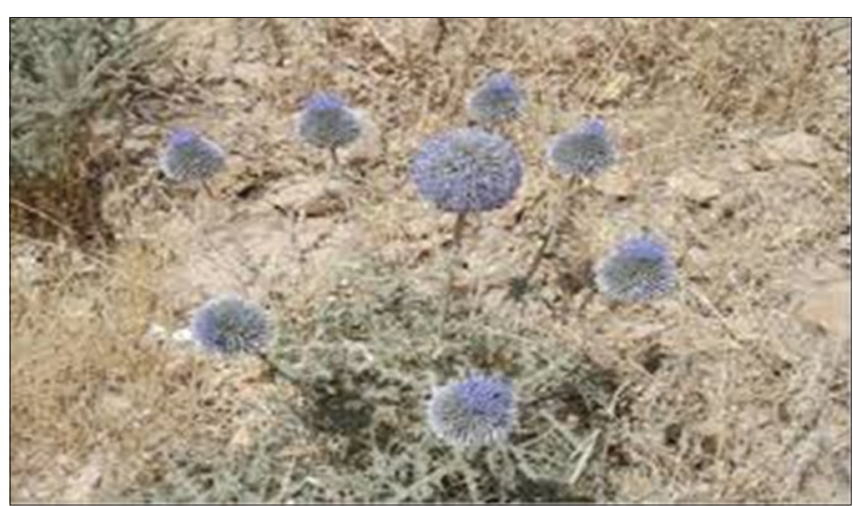

Fig. 1: Iraqi Echinops heterophyllus [4]

\section{Animal scarification, collection of blood, and liver dissection}

At the end of experiment, the rabbits' blood was collected in gel tube under anesthesia by cardiac puncture, left to coagulate, and then centrifuged at $3500 \mathrm{rpm}$ for $15 \mathrm{~min}$ to the separate the serum. The serum activity of liver enzymes such as aspartate aminotransferase (AST), alanine aminotransferase (ALT), alkaline phosphatase (ALP), total serum bilirubin, serum albumin, total serum protein, and oxidative stress markers such as malondialdehyde (MDA) and reduced glutathione (GSH) was measured by commercially available kits. Then, the liver was dissected and placed in $10 \%$ formalin at room temperature for $4 \mathrm{~h}$. Then, the tissue processed and stained by hematoxylin and eosin for histopathological study. The prepared slides were examined under light microscope, to assess the histopathological changes of liver tissue. Semi-quantitative scoring system was applied for the evaluation of liver lesions in drug-induced hepatitis [8] according to Table 1.

\section{Statistical analysis}

Statistical analysis was performed using Statistical Package for the Social Sciences version (23) and Microsoft Excel Worksheet 2016. Crude data were analyzed to obtain the mean \pm standard deviation (SD). Student $t$-test was used to compare between two groups. ANOVA test was used to compare between different groups, followed by Tukey's post hoc analysis. $\mathrm{p} \leq 0.05$ was considered to be statistically significant and $\mathrm{p} \leq 0.001$ considered as highly significant. Mann-Whitney U-test was used for the comparison of histopathological score between two groups.

\section{RESULTS}

Comparison between healthy control group and negative control group in relation to serum liver enzymes, serum total protein (TP), serum albumin, serum total bilirubin, serum GSH, and serum MDA showed significant $(\mathrm{p} \leq 0.05)$ increase in serum total bilirubin, serum ALP, serum ALT, serum AST, and serum MDA and decrease in serum TP, serum Albumin, and serum GSH as shown in Table 2.

The analysis by Mann-Whitney U-test was performed to the histopathological scores between healthy control groups and negative control group - MTX treated-group. The results showed statistically highly significant increase $(\mathrm{p} \leq 0.001)$ in the histopathological score in negative control when compared with healthy control group represented by portal inflammation with periportal interface hepatitis (piecemeal necrosis) as shown in Fig. $2 \mathrm{~b}$.

Comparison between negative control group and MTX+ crude extract of $E$. heterophyllus-treated group in relation to serum proteins, liver enzymes, and oxidative stress markers revealed highly significant decrease $(p \leq 0.001)$ in the level of serum AST in MTX+crude extracttreated group in comparison with negative control group, while statistically significant increase $(p \leq 0.05)$ was observed in the level of serum total protein and serum GSH in MTX+crude extract-treated group in comparison with negative control group. As shown in table 3 (only) as table 4 is for histopathological score comparison.

The analysis of histopathological score revealed statistically significant decrease $(\mathrm{p} \leq 0.05)$ in MTX+crude extract of E. heterophyllus-treated group when compared with the negative control group represented by significant restoration of hepatic architecture with mild portal inflammation of mononuclear cells infiltrate as in Fig. 2c.

Table 1: Scheuer classification for grading of hepatitis (modified) [8]

\begin{tabular}{ll}
\hline Grade & Portal/periportal activity \\
\hline 0 & None \\
1 & Portal inflammation \\
2 & Mild piecemeal necrosis \\
3 & Moderate piecemeal necrosis \\
4 & Severe piecemeal necrosis \\
\hline
\end{tabular}


Comparison between negative control group and MTX+flavonoid fraction of $E$. heterophyllus-treated group in relation to serum proteins, liver enzymes, and oxidative stress markers revealed statistically highly significant increase $(\mathrm{p} \leq 0.001)$ in the level of serum TP, a significant increase in serum GSH and serum ALB, and significant decrease $(\mathrm{p} \leq 0.05)$ in serum ALT in MTX+flavonoid fraction of E. heterophyllustreated group in comparison with negative control group as shown in Table 3 .

The histopathological score analysis revealed statistically significant decrease $(\mathrm{p} \leq 0.05)$ in MTX+flavonoid fraction of $E$. heterophyllus-treated group score when compared with the negative control group, and this is demonstrated by significant restoration of hepatic architecture with mild-to-moderate portal inflammation of mononuclear cells infiltrate as shown in Fig. 2.

\section{HPLC}

HPLC chromatogram of flavonoid fraction is shown in Table 5 and Fig. 3. HPLC scanning profile of $90 \%$ hydroalcoholic extract of flavonoid fraction of $E$. heterophyllus showed quercetine at RT 6.56 as shown in Fig. 4, kaempferol at RT 8.21 as shown in Fig. 5, rutin at RT 7.253 as shown in Fig. 6, and catechin at RT at 11.9 as shown in Fig. 7.

\section{DISCUSSION}

It is well known that chemotherapeutic drugs do not possess full selectivity for cancer cells, making them affect the normal cells with high proliferation rate. This results in many toxic effects on several organs such as bone marrow depression, gastrointestinal side effects, lung fibrosis, nephrotoxicity, and hepatotoxicity and other miscellaneous side effects [9]. Hepatotoxicity is one of the chief side effects of MTX limiting its clinical use [10]. In spite of some vagueness regarding the mechanism of MTX-induced liver injury, there are many studies indicating the oxidative stress and triggering of inflammatory response as being the main causes $[3,11]$. This necessitates looking for agents with probable hepatoprotective properties to ameliorate the toxic effects of MTX

The results of the current study revealed hepatic injury due to MTX administration, as shown by the serum levels of liver enzymes, total bilirubin, TP, and oxidative stress markers.

Serum ALT and AST are the most relevant and applicable indicators of hepatocellular injuries [12]., AST and ALP exist in high concentration in the liver. When heaptopathy occurs, these enzymes leak into the bloodstream in proportion with the extent of liver damage [13]. A major rise in AST, ALT, and ALP signals hepatocellular injury or death [14]. MTX blocks the synthesis of nucleic acids, certain amino acids, and consequently proteins, and this leads to damage of organelles and plasma membranes of the hepatic parenchymal cells, interfering with their function and allowing leakage of enzymes [15]. ALP and bilirubin are sensitive markers for the investigation of biliary function [3]. Total bilirubin level is a marker for extensive liver damage or direct inhibition of biliary transporters [16]. Bilirubin is one of the most useful clinical clues to the severity of necrosis, and its accumulation is a measure of binding, conjugation, and excretory capacity of hepatocyte [13].
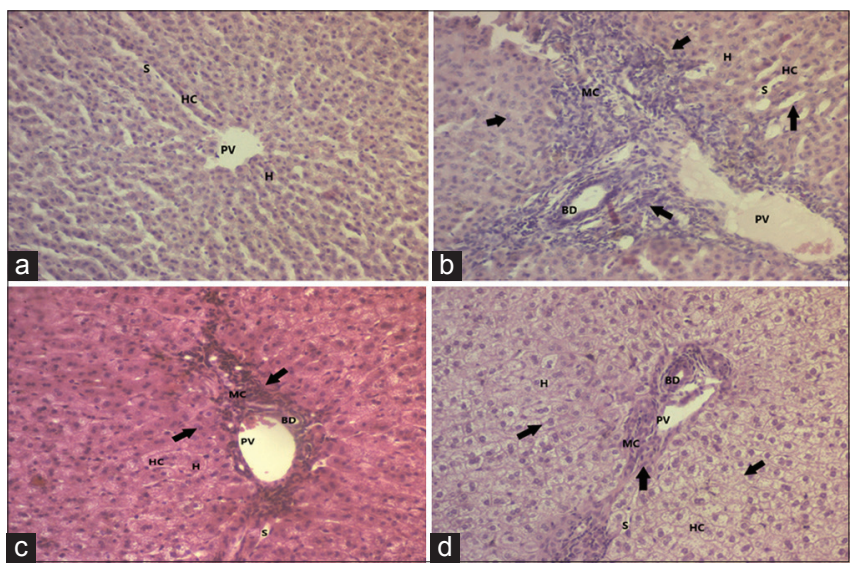

Fig. 2: Histopathological observations (liver sections stained with hematoxylin and eosin, magnification $\times 20$, (a) healthy control: Showing normal hepatic tissue, no portal or periportal inflammation, necrosis or fibrosis, (b) negative control group: Showing portal inflammation with periportal interface hepatitis (piecemeal necrosis), dilated sinusoids and bineucleated hepatocytes (arrows), (c) crude extract of $\boldsymbol{E}$.H.-treated group, showing mild portal inflammation of mononuclear cells infiltrate and bineucleated hepatocytes (arrows), (d) flavonoid fraction of E.H.-treated group: Showing mild portal inflammation of mononuclear cells infiltrate, bineucleated hepatocytes, and hydropic changes(arrows), PV - Portal vein, BD - bile duct, HC - hepatic cord, H - hepatocyte, S - sinusoid, MC - mononuclear cell infiltrate

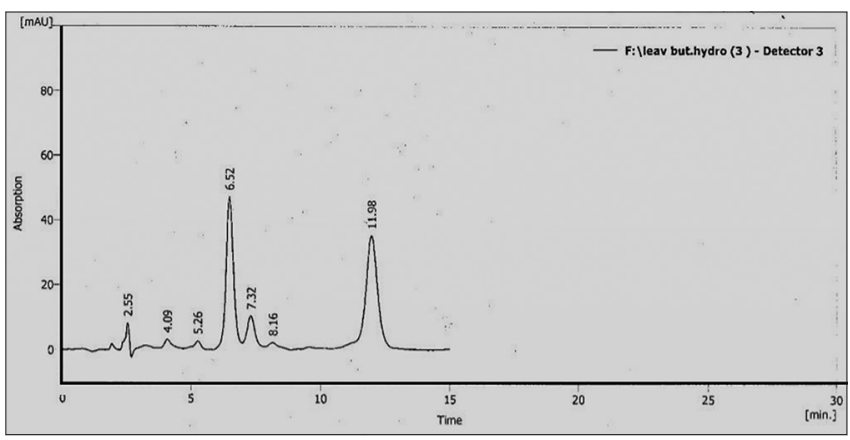

Fig. 3: High-performance liquid chromatography of flavonoid fraction

Table 2: Comparison between healthy control group (Gp1) and negative control group (Gp2) in relation to serum total protein, serum albumin, serum total bilirubin, serum ALP, serum ALT, serum AST, serum GSH, and serum MDA

\begin{tabular}{lll}
\hline Parameter & $\begin{array}{l}\text { Gp1 healthy control (not treated) } \\
\mathbf{n = 8}(\text { mean } \pm \text { SD) }\end{array}$ & $\begin{array}{l}\text { Gp2 negative control (given MTX) } \\
\mathbf{n = 8}(\mathbf{m e a n} \pm \text { SD) }\end{array}$ \\
\hline AST $(\mathrm{u} / \mathrm{l})$ & $99.53 \pm 34.13$ & $41.09 \pm 9.14$ \\
ALT $(\mathrm{u} / \mathrm{l})$ & $73.88 \pm 15.5$ & $50.13 \pm 24.85$ \\
ALP $(\mathrm{u} / \mathrm{l})$ & $59.0 \pm 26.24$ & $26.75 \pm 10.91$ \\
TSB $(\mathrm{mg} / \mathrm{dl})$ & $0.12 \pm 0.05$ & $0.03 \pm 0.02$ \\
S. Alb $(\mathrm{g} / \mathrm{dl})$ & $3.3 \pm 0.26$ & $3.9 \pm 0.37$ \\
TSP $(\mathrm{mg} / \mathrm{dl})$ & $5.35 \pm 0.24$ & $6.21 \pm 0.68$ \\
GSH $(\mu \mathrm{g} / \mathrm{ml})$ & $23.77 \pm 3.56$ & $271.35 \pm 38.94$ \\
MDA $(\mathrm{nmol} / \mathrm{ml})$ & $2.79 \pm 1.28$ & $0.41 \pm 0.43$ \\
\hline
\end{tabular}

*Denote significant difference at $\mathrm{p} \leq 0.05,{ }^{* *}$ denote highly significant difference at $\mathrm{p} \leq 0.001$. AST: Aspartate aminotransferase, ALT: Alanine aminotransferase,

ALP: Alkaline phosphatase, MDA: Malondialdehyde, GSH: Glutathione, S. Alb: Serum albumin, TSP: Total serum protein, E.H.: Echinops heterophyllus, STP: Serum total protein 
Table 3: Comparison between negative control, MTX+crude extract of E.H.-treated, and MTX+flavonoid fraction of E.H.-treated groups by unpaired t-test

\begin{tabular}{|c|c|c|c|}
\hline Parameters & Negative control & MTX+crude extract of $E . H$. & MTX+flavonoid fraction of $E . H$. \\
\hline \multicolumn{4}{|l|}{$\operatorname{AST}(\mathrm{u} / \mathrm{l})$} \\
\hline Mean \pm SD & \multirow[t]{2}{*}{$99.53 \pm 34.13$} & $39.78 \pm 24.03$ & $74.34 \pm 28.52$ \\
\hline $\mathrm{p}$ value & & 0.001 & 0.131 \\
\hline \multicolumn{4}{|l|}{$\operatorname{ALT}(\mathrm{u} / \mathrm{l})$} \\
\hline Mean \pm SD & \multirow[t]{2}{*}{$73.88 \pm 15.5$} & $51.5 \pm 19.81$ & $54.0 \pm 20.61$ \\
\hline $\mathrm{p}$ value & & 0.025 & 0.047 \\
\hline \multicolumn{4}{|l|}{$\operatorname{ALP}(\mathrm{u} / \mathrm{l})$} \\
\hline $\mathrm{p}$ value & $59.0 \pm 26.24$ & 0.083 & 0.398 \\
\hline \multicolumn{4}{|l|}{ TSB ( mg/dl) } \\
\hline Mean \pm SD & \multirow[t]{2}{*}{$0.12 \pm 0.05$} & $0.07 \pm 0.04$ & $0.08 \pm 0.04$ \\
\hline $\mathrm{p}$ value & & 0.035 & 0.128 \\
\hline \multicolumn{4}{|l|}{ S. ALB (g/dl) } \\
\hline Mean \pm SD & \multirow[t]{2}{*}{$3.3 \pm 0.26$} & $3.59 \pm 0.33$ & $3.74 \pm 0.43$ \\
\hline $\mathrm{p}$ value & & 0.073 & 0.029 \\
\hline \multicolumn{4}{|l|}{ TSP (g/dl) } \\
\hline $\mathrm{p}$ value & $5.35 \pm 0.24$ & 0.022 & 0.001 \\
\hline \multicolumn{4}{|l|}{ 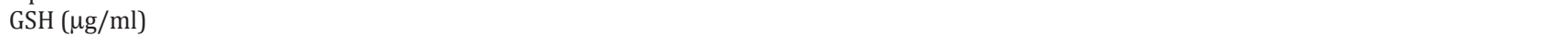 } \\
\hline Mean \pm SD & \multirow[t]{2}{*}{$23.77 \pm 3.56$} & $179.62 \pm 133.87$ & $51.43 \pm 29.46$ \\
\hline $\mathrm{p}$ value & & 0.005 & 0.020 \\
\hline \multicolumn{4}{|c|}{$\mathrm{MDA}(\mathrm{nmol} / \mathrm{ml})$} \\
\hline Mean \pm SD & \multirow[t]{2}{*}{$2.79 \pm 1.28$} & $1.12 \pm 1.06$ & $2.06 \pm 0.96$ \\
\hline $\mathrm{p}$ value & & 0.013 & 0.216 \\
\hline
\end{tabular}

${ }^{*}$ Denote significant difference at $\mathrm{p} \leq 0.05,{ }^{* *}$ denote highly significant difference at $\mathrm{p} \leq 0.001$. AST: Aspartate aminotransferase, ALT: Alanine aminotransferase, ALP: Alkaline phosphatase, TSB: Total serum bilirubin, S. Alb: Serum albumin, TSP: Total serum protein, GSH: Reduced glutation, MDA: Malondialdehyde, E.H.: Echinops heterophyllus

Table 4: Comparison of histopathological scores between healthy control group, negative control group-MTX-treated,

MTX+crude extract of Echinops heterophyllus treated, and flavonoid fraction of Echinops heterophyllus-treated groups by Mann-Whitney U-test

\begin{tabular}{lllll}
\hline Score & $\begin{array}{l}\text { Negative } \\
\text { control }\end{array}$ & $\begin{array}{l}\text { Healthy } \\
\text { control }\end{array}$ & $\begin{array}{l}\text { MTX+crude } \\
\text { extract of } \boldsymbol{E} . \boldsymbol{H} \text {. }\end{array}$ & $\begin{array}{l}\text { MTX+flavonoid } \\
\text { fraction of } \boldsymbol{E} . \boldsymbol{H} .\end{array}$ \\
\hline Median & 2.5 & 0.0 & 1.0 & 0.5 \\
Range & $1-3$ & $0-1$ & $0-2$ & $0-2$ \\
p value & & $<0.001$ & 0.007 & 0.002 \\
\hline
\end{tabular}

E.H.: Echinops heterophyllus

Table 5: Retention time of flavonoid compounds

\begin{tabular}{ll}
\hline Standard & Retention time (min) \\
\hline Quercetine & 6.56 \\
Kaempferol & 8.21 \\
Catechin & 11.9 \\
Rutin & 7.253 \\
\hline
\end{tabular}

Decreasing in albumin and increasing bilirubin levels specify hepatotoxicity and compromised liver function due to the MTX-induced hepatocellular injury [14]. In the current study, administration of MTX $20 \mathrm{mg} / \mathrm{kg}$ for three successive days resulted in significant raise in serum activity of liver enzymes (AST, ALT, and ALP), as well as elevation of serum total bilirubin level. On the other hand, we noticed asignificant decrease in the concentration of serum albumin and TP. These results were consistent with previous studies of Famurewa et al. and Ali et al., who demonstrated that the MTX-induced liver injury is characterized by significant raise in serum levels of AST, ALT, and ALP due to alteration in hepatic transport function and membrane permeability, leading to leakage of marker enzymes from the cells, and also decrease in ALB (albumin) and TP indicating deteriorated hepatic synthetic function. The resultant hepatotoxicity due to MTX administration was further confirmed by the histological alterations [17].

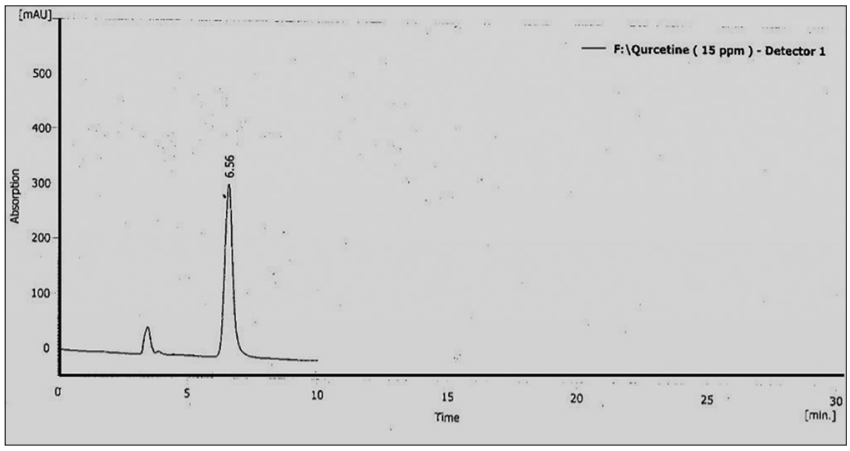

Fig. 4: High-performance liquid chromatography of quercetine standard

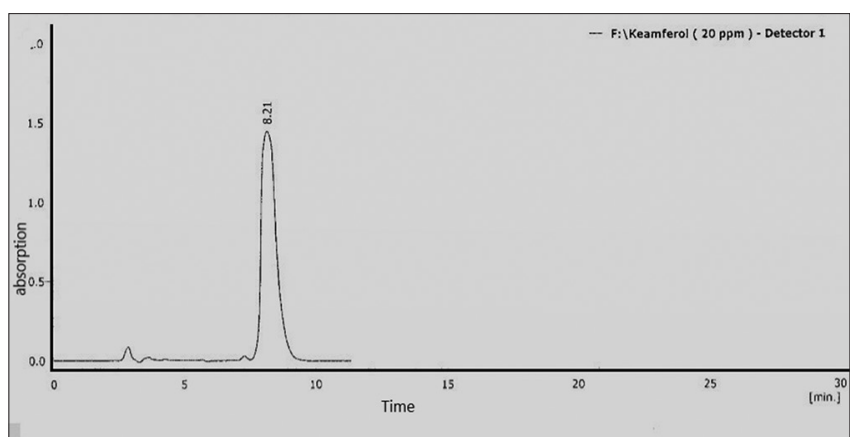

Fig. 5: High-performance liquid chromatography of kaempferol standard

Oxidative stress is the main cause of the tissue damage caused by MTX, and it results due to the imbalance between production of reactive oxygen species (ROS) and antioxidant defense system (GSH) due to excess production of ROS [18] such as superoxide radical, hydrogen peroxide, and hydroxyl radical, which pushes cell toward oxidative 


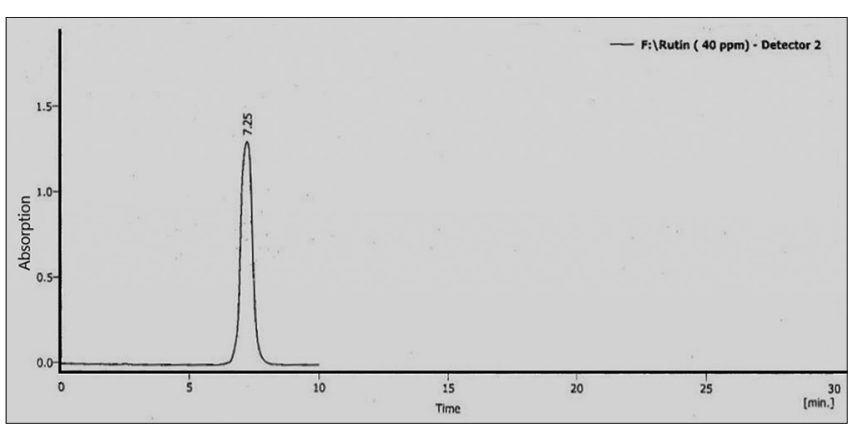

Fig. 6: High-performance liquid chromatography of rutin standard

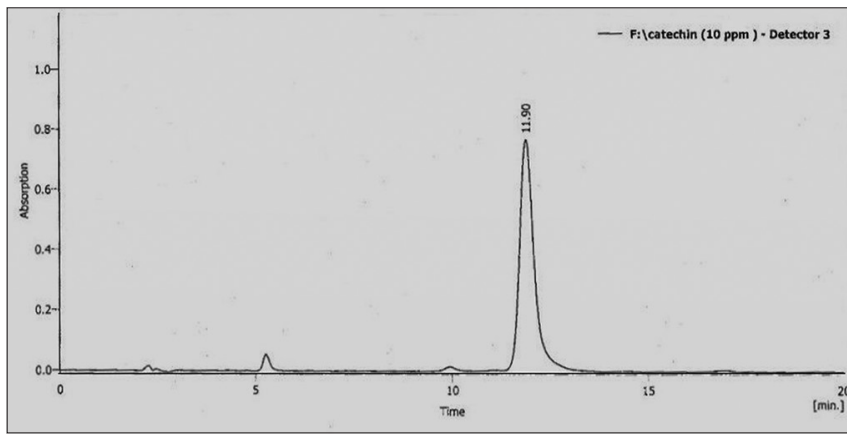

Fig. 7: High-performance liquid chromatography of catechin standard

stress [10], due to exhaustion of mitochondrial enzymatic and nonenzymatic antioxidants machinery [3], enhancing the generation of ROS and nitrogen species, preventing cytosolic NADP-dependent dehydrogenase and NADP malic enzyme, causing decrease in the levels of glutathione, superoxide dismutase, and catalase, and ultimately decreasing the effectivity of the antioxidant defence system responsible for protecting the cell against ROS $[11,15]$.

Reduced nicotinamide adenine dinucleotide phosphate (NADPH) is used by glutathione (GSH) reductase to maintain the reduced state of cellular GSH which is an important antioxidant present in cytosol. Recent evidence demonstrate that MTX administration triggers a reduction in NADPH and GSH and upregulates ROS and hepatotoxic manifestations associated with decreased cellular antioxidant defense system, resulting in hepatic oxidative damage, membrane degradation, and cellular dysfunction [10]. In the current study, there was a significant reduction in the level of serum GSH. This finding was consistent with the study of Famurewa et al., who found that MTX administration elicited significant reduction in hepatic activities of SOD, CAT, GPX, and GSH [3], and the studies of Turgut et al., Rath et al., and Wu et al., who found that oxidative hepatocellular damage leads to reduced levels of liver and serum GSH $[19,20]$.

It was found that MTX-induced toxicity was associated with rises in lipid peroxidation in several tissues, such as liver, kidney, and ileum [10]. Lipid peroxidation plays a crucial role in cell membrane damage [15]. MTX can bind lipids in a cell membrane (containing unsaturated fatty acids, nucleic acids, and proteins) [21] or may generate superoxide anions and highly reactive hydroxyl radicals and their derivatives [6], and these free radicals react with membrane lipids and poly-unsaturated fatty acids beginning lipid peroxidation and cell death [14]. MDA is a metabolite of polyunsaturated fatty acid peroxidation and is a reliable indicator of the degree of lipid peroxidation [3]. In the current study, there was a significant rise in the level of MDA indicating the lipid peroxidation and cell membrane damage due to MTX administration, and this observation was in consistence with the study of Mehrzadi et al., which showed that MTX rises hepatic MDA levels, indicating that MTX results in oxidative damage to the lipids and proteins of the liver and leads to structural and functional changes in antioxidant enzymes [11]. Furthermore, a study of Turgut et al. revealed that hepatotoxicity and lipid peroxidation lead to increased level of MDA in the liver and serum [19]. Many studies had revealed that hepatotoxic agents which create an oxidative stress in the hepatocytes are accompanied with raise in serum MDA $[22,23]$.

The histopathological observation of the MTX-administered group revealed inflammatory reactions and cell death signs, ranging from mild hepatitis to severe piecemeal necrosis (also known as "interface hepatitis") in most samples.

Similar observations have been revealed in the study of Mahmoud et al. and Hafez et al., who showed that MTX-induced inflammatory cell infiltration, severe hepatocyte degeneration, bile duct hyperplasia, hyperemia, sinusoidal dilatation, and necrosis [24].

Increased oxidative stress accompanied with dramatic decline in cellular antioxidant defense system is the main cause of the tissue damage caused by MTX through induction of morphological and functional changes in the liver tissue [6,11]. MTX-triggered production of ROS stimulates the accumulation of leukocytes in tissues, indirectly exacerbates tissue injury through activated neutrophils, and thus induces marked, non-specific hepatic lesions, such as congestion and dilatation of sinusoids, cytoplasmic hydropic and fatty vacuolation, focal necrosis, and portal inflammation [25].

The results of the present study showed a significant protective effect of the crude extract of $E$. heterophyllus on hepatic function. There was a significant prevention of MTX-induced hepatotoxicity in the group receiving crude extract of $E$. heterophyllus, manifested by decreased serum liver enzyme activities and total bilirubin concentration, and this was accompanied with restoration of hepatocytes synthetic function appeared as raise in serum level of albumin and TP. Furthermore, the antioxidant effect of the crude extract of $E$. heterophyllus was obvious through the significant raise in serum GSH level as well as serum MDA decline.

These findings indicate that the crude extract of E. heterophyllus possesses an antioxidant as well as hepatoprotective activity. These actions can be attributed to many phytochemical constituents present in E. heterophyllus, such as flavonoids, terpenoids, and quinolin alkaloids.

The histopathological examination of the MTX+crude extract of E. heterophyllus-treated group showed obvious improvement in the histopathological score, manifested mainly by decreased number of inflammatory cells infiltrated to the liver tissue and decreased hepatocyte damage. This observation reflects the anti-inflammatory action and healing properties of $E$. heterophyllus crude extract. A previous study done on E. heterophyllus extract had shown similar effects on wound healing, and it revealed that applying crude extract of E. heterophyllus plant accelerated wound healing and repair [4].

The treatment of MTX-intoxicated rabbits with flavonoid fraction of E. heterophyllus showed significant hepatoprotective effect through significant decreased level of serum liver enzyme ALT; furthermore, there was an increase in the concentration of STP and albumin in comparison with the negative control indicating prevention of hepatotoxicity and restored synthetic function of the liver and reduced albumine loss through the kidney due to MTX-induced nephrotoxicity [15]. The flavonoids possess 15 carbon skeleton (benzopyran) C6-C3-C5 backbone structure, and it is composed of two benzene rings, called ring A and ring B bridged by heterocyclic ring called ring C [26]

Flavonoids reveal high antioxidant activity, protecting tissues from damage caused by ROS, reducing oxidative stress markers like MDA [27]. The mechanisms include direct scavenging of ROS, stimulation of antioxidant enzymes like SOD, and inhibition of oxidases (such as NADPH oxidase) dependent production of superoxide anion and other ROS $[28,29]$. 
Flavonoids have been shown to have protective effects against druginduced toxicity [30]. The present results were consistent with a previous study which showed similar results after treatment of CCl4induced hepatotoxicity with seed extract of Echinops tenuisectus containing high concentration of flavonoids, by decreased AST and ALT levels, and this observation was attributed to the hepatoprotective effect of flavonoids which possess antioxidant properties resulting in improvement in the normal physiology of hepatocyte [7]. In many other studies, the antioxidant and hepatoprotective effect of flavonoids extracted from diverse plants were represented by a raise in GSH and a decline in MDA levels in CCl4-induced [7,31] as well as MTX-induced hepatotoxicity models [6].

In the current study, flavonoid fraction of E. heterophyllus exerted a protective effect on the liver tissue, lowering the histopathological scores and regaining the nearly normal architecture of liver tissue as well as decreased the number of inflammatory cells infiltrated. This observation was in agreemen with several previous studies on flavonoids extracted from diverse plant species, such as Abdulrazzaq et al., (2008) study which revealed that Pre-treatment of rats with flavonoids rich seed extract of Echinops tenuisectus before CCl4 intoxication obviously decreased the CCl4 induced hepatic injury [31]. a study done by Gupta et al., (2015), revealed the hepatoprotective activity of flavonoid fraction of three indian herbs [32], and the study of Pattanayak et al., on herbal flavonoid extract showed significant improvement in the histopathological features of flavonoid-treated groups in comparison with negative control group in an acetaminopheninduced liver toxicity, while Wu et al., showed similar activity of total flavonoids of Laggera alata on a CCl4-induced liver toxicity model. Based on these observations, it is concluded that the hepatoprotective effect of flavonoids is a result of their antioxidant and, hence, antiinflammatory properties [33].

\section{HPLC}

Modern HPLC uses high pressure to force the mobile phase and an analyte through a closed column packed with micron-size particles, which constitute the stationary phase [34].

HPLC, in this study, showed different bands in ethanol extract of flavonoids of E. heterophyllus with different RT value under UV light at $265 \mathrm{~nm}$. These bands indicate the presence of quercetine, rutin, keampferol, and catechin compounds as mentioned in results.

\section{CONCLUSIONS}

The current study showed that the crude extract of E. heterophyllus and flavonoid fraction of $E$. heterophyllus had exerted hepatoprotective activity through their positive effects on liver function tests, oxidative stress, and histopathological scores. The crude extract of E. heterophyllus has more potent hepatoprotective effect due to the presence of many hepatoprotective phytochemicals.

\section{ACKNOWLEDGMENTS}

Special thanks to Assist. Prof. Dr. Enas Jawad Kdhim a chairman of the Department of Pharmacognosy in the College of Pharmacy, Baghdad University, lecturer Dr. Shihab Abdulrahman, Assist. Prof. Dr. Abdulkareem Hameed, and Pharmacology Department staff at Al-Nahrain University, College of Medicine, for their support in this research.

\section{AUTHORS' CONTRIBUTIONS}

Ahmed Abu Raghif has provided the design, intellectual content, innovation, and protocol for conducting the experiment in the laboratory along with mentorship. Heba Abdulmohsen has majorly performed the experiment in the laboratory and analysis of obtained data, and Mohammed Jabbar Manna had a role in laboratory herbal extract preparation process.

\section{CONFLICTS OF INTEREST}

The authors declare that there are no conflicts of interest regarding the publication of this article.

\section{REFERENCES}

1. Rider BJ. Methotrexate. Ref Modul Biomed Sci 2007;1:1-5.

2. Vohra R, Vohra SS, Grock A, Mason J. Working through the paradox of methotrexate toxicity. Ann Emerg Med 2018;72:129-32.

3. Famurewa AC, Ufebe OG, Egedigwe CA, Nwankwo OE, Obaje GS. Virgin coconut oil supplementation attenuates acute chemotherapy hepatotoxicity induced by anticancer drug methotrexate via inhibition of oxidative stress in rats. Biomed Pharmacother 2017;87:437-42.

4. Abdulrasool AA, Fahmi ZM, Khadeem EJ. A relative assess on wound healing and anti scar activity of crude echinops heterophyllus extract and some of its bioactive fractions. Int J Pharm Pharm Sci 2013;5:468-75.

5. Fahmi ZM, Khadeem EJ, Hasan HF, Luaibi OK. The Antibacterial effect of phytosterols isolated from echinops heterophyllus in comparison with mebo ${ }^{\circledR}$ and standard antimicrobial agents. Am J Polit Sci 2014;14:6-8.

6. Famurewa AC, Folawiyo AM, Epete MA, Igwe EC, Okike PI, Maduagwuna EK, et al. Abrogation of hepatic damage induced by anticancer drug methotrexate by zobo (Hibiscus sabdariffa extract) supplementation via targeting oxidative hepatotoxicity in rats. J Diet Suppl 2018:1-3.

7. Abdulrazzaq MH, Khadeem EJ, Muhammadi SS. Hepatoprotective effect of Echinops tenuisectus (Compositae) on $\mathrm{CCl} 4$ induced hepatic damage in rats. Iraqi J Pharm Sci 2008;17:16-24

8. Theise ND. Liver biopsy assessment in chronic viral hepatitis: A personal, practical approach. Mod Pathol 2007;20 Suppl 1:S3-14.

9. Wood GS, Wu J. Methotrexate and pralatrexate. Dermatol Clin 2015;33:747-55.

10. Ali N, Rashid S, Nafees S, Hasan SK, ShahidA, Majed F, et al. Protective effect of chlorogenic acid against methotrexate induced oxidative stress, inflammation and apoptosis in rat liver: An experimental approach. Chem Biol Interact 2017;272:80-91.

11. Mehrzadi S, Fatemi I, Esmaeilizadeh M, Ghaznavi H, Kalantar H, Goudarzi M, et al. Hepatoprotective effect of berberine against methotrexate induced liver toxicity in rats. Biomed Pharmacother 2018;97:233-9.

12. Khalifa MM, Bakr AG, Osman AT. Protective effects of phloridzin against methotrexate-induced liver toxicity in rats. Biomed Pharmacother 2017;95:529-35.

13. Pattanayak S, Nayak SS, Panda DP, Dinda SC. Hepatoprotective activity of crude flavonoids extract of Cajanus scarabaeoides (L) in paracetamol intoxicated albino rats. Asian $\mathrm{J}$ Pharm Biol Res 2011;1:22-7.

14. Mahmoud AM, Hussein OE, Hozayen WG, Abd El-Twab SM. Methotrexate hepatotoxicity is associated with oxidative stress, and down-regulation of PPAR $\gamma$ and nrf2: Protective effect of 18ß-glycyrrhetinic acid. Chem Biol Interact 2017;270:59-72.

15. Kumari S. Methotrexate induced hepatotoxicity and its management. Int J Sci Res 2013;14:2319-7064

16. Fontana RJ. Reviews in basic and clinical gastroenterology. Gastroenterology 2014;146:914-28.

17. Ali F, Khan KM, Salar U, Taha M, Hadiani N, Wadood A, et al. Protective effect of Chlorogenic acid against methotrexate induced oxidative stress, inflammation and apoptosis in rat liver: An experimental approach. Eur J Med Chem 2017;272:80-91

18. Arul DJ, Das S, Jayan N, Asha DS. Protective activity of asparagus racemosus in methotrexate-induced liver toxicity in wistar rats. Asian J Pharm Clin Res 2018;11:9-12.

19. Turgut G, Enli Y, Kaptanoğlu B, Turgut S, Genç O. Changes in the levels of MDA and GSH in mice serum, liver and spleen after aluminum administration. East J Med 2006;11:7-12.

20. Rath D, Prusty S, Sahu PK. Hepatoprotective effects of cassia tora whole plant. Int J Pharm Technol 2016;3:2798-806.

21. Pınar N, Kaplan M, Özgür T, Özcan O. Ameliorating effects of tempol on methotrexate-induced liver injury in rats. Biomed Pharmacother 2018;102:758-64.

22. Baghel SS, Mavai Y, Baghel RS, Sikarwar I, Shrivastava N. Evaluation of hepatoprotective efficacy of rhizomes Curcuma caesia in paracetamol induced hepatotoxicity in rats. Int J Pharm Pharm Sci 2013;5:249-55.

23. Cuce G, Çetinkaya S, Koc T, Esen HH, Limandal C, Balcı T, et al. Chemoprotective effect of vitamin $\mathrm{E}$ in cyclophosphamide-induced hepatotoxicity in rats. Chem Biol Interact 2015;232:7-11. 
24. Hafez HM, Ibrahim MA, Ibrahim SA, Amin EF, Goma W, Abdelrahman AM, et al. Potential protective effect of etanercept and aminoguanidine in methotrexate-induced hepatotoxicity and nephrotoxicity in rats. Eur J Pharmacol 2015;768:1-2.

25. Khafaga AF, El-Sayed YS. Spirulina ameliorates methotrexate hepatotoxicity via antioxidant, immune stimulation, and proinflammatory cytokines and apoptotic proteins modulation. Life Sci 2018;196:9-17.

26. Hasan HT, Kadhim EJ. Phytochemical investigation of leaves and seeds of Corchorus olitorius 1. Cultivated in Iraq. Asian J Pharm Clin Res 2018;11:3-12.

27. García ER, Gutierrez EA, de Melo FCSA, Novaes RD, Gonçalves RV. Flavonoids effects on hepatocellular carcinoma in murine models: A systematic review. Evid Based Complement Alternat Med 2018;2018:6328970.

28. Verri WA, Vicentini FT, Baracat MM, Georgetti SR, Cardoso RD, Cunha TM, et al. Flavonoids as anti-inflammatory and analgesic drugs: Mechanisms of action and perspectives in the development of pharmaceutical forms. Bioact Nat Prod 2012;36:297-330.
29. Xiang C, Teng Y, Yao C, Li X, Cao M, Li X, et al. Antioxidant properties of $\mathrm{fl}$ avonoid derivatives and their hepatoprotective effects on $\mathrm{CCl} 4$ induced acute liver injury in mice. R Soc Chem 2018;8:15366-71.

30. Khan H, Jawad M, Kamal MA, Baldi A, Xiao J, Nabavi SM, et al. Evidence and prospective of plant derived flavonoids as antiplatelet agents: Strong candidates to be drugs of future. Food Chem Toxicol 2018;119:355-67.

31. Abdulrazzaq MH, Khadeem EJ, Muhammadi SS. Hepatoprotective activity of bioherbal ethanolic extract on $\mathrm{CCl} 4$ induced hepatic damage in rats. Iraqi J Pharm Sci 2008;17:61-5.

32. Gupta A, Sheth NR, Pandey S, Yadav JS, Joshi SV. Screening of flavonoids rich fractions of three Indian medicinal plants used for the management of liver diseases. Braz J Pharmacogn 2015;25:485-90.

33. Wu Y, Wang F, Zheng Q, Lu L, Yao H, Zhou C, et al. Hepatoprotective effect of total flavonoids from Laggera alata against carbon tetrachloride-induced injury in primary cultured neonatal rat hepatocytes and in rats with hepatic damage. J Biomed Sci 2006;13:569-78.

34. Stevenson R. Instrumentation. J Chromatogr Libr 2004;69:469-518. 